\title{
ANÁLISE DE SUBCULTURAS EM UMA ORGANIZAÇÃO DO TERCEIRO SETOR
}

\author{
André Luiz Mendes Athayde ${ }^{1}$ \\ Mateus Pereira Santos ${ }^{2}$ \\ Recebido em: 04 fev. 2019 \\ Aceito em: 16 abr. 2019
}

\begin{abstract}
Como citar este artigo: ATHAYDE, André Luiz Mendes; SANTOS, Mateus Pereira. ANÁLISE DE SUBCULTURAS EM UMA ORGANIZAÇÃO DO TERCEIRO SETOR. Revista Visão: Gestão

Organizacional, Caçador, SC, Brasil, p. 157-173, jun. 2019. ISSN 2238-9636. Disponível em: <http://dx.doi.org/10.33362/visao.v8i1.1914>.
\end{abstract}

Resumo: A cultura funciona como um mecanismo que traz coesão a um grupo e, no contexto organizacional, quanto mais convergentes se mostram os seus colaboradores entre si, mais forte é a sua cultura e menos conflitos e desgastes se espera encontrar em suas práticas laborais. A presente pesquisa, através de um estudo multicaso, objetivou verificar se existem diferenças entre as culturas organizacionais instaladas em duas empresas regionais de uma organização do terceiro setor, significativas a ponto de caracterizarem duas distintas subculturas. Realizou-se um diagnóstico cultural, baseando-se em quatro dimensões internacionalmente conhecidas e difundidas por Geert Hofstede, a saber: Índice de Distância Hierárquica, Índice de Individualismo, Índice de Masculinidade e Índice de Controle da Incerteza. Para tanto, desenvolveu-se uma pesquisa quantitativa-descritiva, utilizando-se uma escala de dimensões culturais já validada em estudos relevantes prévios. Os resultados encontrados jogaram luz na hipótese de que, mesmo que uma organização se esforce no sentido de disseminar seus valores culturais, objetivando que seus colaboradores assumam pensamentos uníssonos e consoantes com os objetivos institucionais, a existência de subculturas dentro de uma organização pode fazer, por exemplo, com que empresas filiais de uma organização matriz apresentem particularidades que desviem, em maior ou menor grau, dos valores desta. Isso, em última análise, pode prejudicar o alcance dos objetivos organizacionais. Uma das principais reflexões e contribuições levantadas por este trabalho diz respeito ao fato de que as peculiaridades de cada cultura organizacional precisam ser levadas em consideração quando do estabelecimento de objetivos e métricas de controle.

Palavras-Chave: Cultura Organizacional. Dimensões Culturais. Terceiro Setor.

ANALYSIS OF SUBCULTURES IN A THIRD-SECTOR ORGANIZATION

Abstract: Culture works as a mechanism that brings cohesion to a group and, in the organizational context, the more convergent the employees are, the stronger their culture and the fewer conflicts and wastes they are expected to find in their work practices. The present research, through a multicase study, aimed to verify if there are

\footnotetext{
${ }^{1}$ Universidade de Brasília (UnB) - Doutorando em Administração (PPGA/UnB), Universidade Federal de Minas Gerais (UFMG) - Professor do Magistério Superior - Dedicação Exclusiva. E-mail: andreluizathayde@outlook.com. ${ }^{2}$ Universidade Federal de Minas Gerais (UFMG). E-mail: mateuspereira_1414@hotmail.com.
} 
differences between the organizational cultures installed in two regional companies of a third sector organization, significant to the point of characterizing two different subcultures. A cultural diagnosis was made, based on four dimensions internationally known and diffused by Geert Hofstede, namely Hierarchical Distance Index, Individualism Index, Masculinity Index and Uncertainty Control Index. For that, a quantitativedescriptive research was developed, using a scale of cultural dimensions already validated in previous relevant studies. The results found have shed light on the hypothesis that, even if an organization strives to disseminate its cultural values, aiming its collaborators to assume unified and consonant thoughts with institutional objectives, the existence of subcultures within an organization can, for example, subsidiaries of a headquarters organization have particularities which deviate, to a greater or lesser extent, from the values of the latter. This can ultimately undermine the achievement of organizational goals. One of the main reflections and contributions raised by this work concerns the fact that the peculiarities of each organizational culture need to be taken into account when establishing control objectives and metrics.

Keywords: Organizational Culture. Cultural Dimensions. Third Sector.

\section{INTRODUÇÃO}

A cultura é a principal característica humana que diferencia o homem dos outros seres vivos. Ela não é proveniente de herança genética, mas é construída no meio social por meio do compartilhamento de informações, saberes e vivência. Sob outra possível perspectiva, a cultura também pode ser vista como um mecanismo para governar o comportamento, sendo uma forma de, por exemplo, padronizar os modos de agir para atingir objetivos organizacionais (LARAIA, 2009). Assim, a partir desse conceito inicial, pode-se entender que cada indivíduo, proveniente de meios sociais diferentes, possui valores, crenças, costumes, saberes e vivências possivelmente diferentes e isso, como consequência, traz à existência culturas não idênticas. As organizações, nessa ótica, podem ser consideradas exemplos de ambientes em que colaboradores com construção cultural diferente convivem conjuntamente. Esse fato traz às organizações um desafio na gestão das pessoas que a compõem e na gestão da cultura que é construída no interior da mesma.

Srour (1998) $)^{3}$ argumenta que a cultura manifesta as características intrínsecas das organizações. À medida que as empresas conseguem trabalhar tal cultura como mecanismo de controle, com a finalidade de conduzir seus membros no sentido atingir seus objetivos organizacionais, influenciando o seu modo de agir, esta adquire uma cultura favorável e cada vez mais forte. Schein (2009), por sua vez, afirma que a implementação da gestão da cultura organizacional, no sentido de torná-la mais forte e robusta, leva os indivíduos a assumirem pensamentos uníssonos, consoantes com os objetivos institucionais e contribui para o desenvolvimento de um ambiente com menos conflitos e desgastes, maior sinergia no esforço

\footnotetext{
${ }^{1}$ A obra de Srour (1998) é considerada um clássico no campo de estudos culturais.
} 
conjunto, voltado ao alcance de metas e objetivos organizacionais. Para isso, no entanto, é importante que a organização adquira conhecimento sobre sua própria cultura e entenda as motivações daqueles indivíduos que a compõem.

Nesse cenário, o diagnóstico da cultura organizacional se apresenta como uma importante ferramenta cuja principal finalidade é mapear os traços culturais de uma organização, trazendo à tona informações e conhecimentos sobre a mesma que a auxiliarão na gestão de sua cultura e nos seus processos de tomada de decisão, com análises mais assertivas, culminando em desempenho mais eficaz (RUSSO, 2010). Dessa maneira, percebe-se que a cultura, a sua construção, os seus impactos, mudanças e influências são assuntos que, no que tange às organizações, merecem atenção e esforço em estudos organizacionais com a finalidade de fortalecer as mesmas no enfrentamento dos desafios que surgem dos conflitos culturais e de desenvolver estratégias para gerir a cultura interna, transformando-a em vantagem competitiva.

Dentre a diversidade de organizações existentes, há aquelas cujos objetivos não se resumem em ter, no fim de um período de tempo, resultado financeiro positivo. Conhecidas como organizações do terceiro setor, elas visam desenvolver trabalhos de interesse público. Além de desenvolverem competência para a sua sustentabilidade financeira, as mesmas precisam desenvolver trabalhos que atinjam os objetivos sociais para os quais estas organizações foram criadas. De acordo com Falconer (1999), as organizações do terceiro setor possuem cultura diferenciada, com padrões próprios, quando comparadas com organizações do setor público e empresas privadas com finalidade de lucro. Assim, diante desses objetivos norteadores de uma organização do terceiro setor, percebe-se que a gestão da cultura organizacional pode ser uma ferramenta de suma importância para o desenvolvimento de seus objetivos, uma vez que os indivíduos que a compõem precisam estar voltados para o sucesso do trabalho que desenvolvem.

Todavia, mesmo que uma organização se esforce no sentido de disseminar seus valores culturais, objetivando que seus colaboradores assumam pensamentos uníssonos e consoantes com os objetivos institucionais (SHEIN, 2009), a existência de subculturas dentro de uma organização pode fazer, por exemplo, com que empresas filiais de uma organização matriz apresentem particularidades que desviem, em maior ou menor grau, dos valores desta. Segundo Morgan (2006), subculturas são comportamentos e características próprias de grupos ou departamentos que se distinguem dentro de uma organização. Triandis (2002) corrobora essa ideia ao destacar que podem existir várias subculturas em uma mesma organização e isso se dá porque os indivíduos que compõem as subculturas compartilham alguns elementos que se diferem de um grupo para o outro, mesmo que apresentem outros elementos que trazem identidade entre elas.

Nessa verve, levando-se em consideração que cada organização filial de uma empresa 
matriz pode representar uma subcultura organizacional, e levando-se em conta que empresas do terceiro setor possuem valores culturais que as distinguem de empresas de outros setores, haja vista que buscam desenvolver trabalhos de interesse público, a presente pesquisa apresentou a seguinte questão norteadora: existem realmente diferenças significativas na cultura organizacional de duas regionais de uma organização do terceiro setor a ponto de serem consideradas subculturas? O presente estudo, portanto, teve como objetivo geral verificar se existem diferenças significativas entre as culturas organizacionais em duas organizações regionais pertencentes a uma empresa do terceiro setor. Subsidiando o alcance do objetivo supracitado, estabeleceram-se os seguintes objetivos específicos: identificar bases teóricas que sustentem o trabalho; aplicar questionário com escala de mensuração da cultura organizacional aos colaboradores de duas regionais localizadas no norte do estado de Minas Gerais (MG) e na região metropolitana de Belo Horizonte-MG, tomadas como unidades de análise no presente estudo; comparar as dimensões culturais das organizações sob análise com as principais características culturais brasileiras apontadas pela literatura.

A seguir, será apresentada a fundamentação teórica do trabalho, por meio da caracterização de conceitos-macro como cultura, cultura organizacional, cultura brasileira, gestão da cultura organizacional, diagnóstico cultural, dimensões culturais e a contextualização do terceiro setor. Posteriormente, serão apresentados os procedimentos metodológicos, tais como instrumento de coleta de dados e demais caracterizações da pesquisa, seguidos da análise dos resultados. Por fim, apresentar-se-ão as considerações finais do estudo.

\section{FUNDAMENTAÇÃO TEÓRICA}

\section{CULTURA ORGANIZACIONAL E DIAGNÓSTICO CULTURAL}

O termo 'Cultura Organizacional' foi desenvolvido no fim do Século XVIII, sendo aceito e utilizado somente um século depois. Pesquisas iniciais sobre o tema foram desenvolvidas somente em meados de 1930, com a experiência de Hawthorne, na Western Eletric Company, nos Estados Unidos, por Elton Mayo e Willian Warner. Porém, somente depois de 1950 que surgiram estudos aprofundados e mais específicos sobre a cultura das organizações (RUSSO, 2010).

A cultura organizacional é expressa, segundo Aktouf (2007), pela ligação do mundo material, que são as vivências concretas, com o mundo imaterial, que é representado pelo universo simbólico e suas representações, através de representações mentais na coletividade. Tal cultura varia de acordo com o grupo analisado, seus comportamentos e hábitos (MOTTA; CALDAS, 1997). De acordo com Freitas (2005), a cultura organizacional pode ser compreendida como $m$ conjunto de representações imaginárias e sociais que se constroem nas relações 
cotidianas dentro da organização. Srour (1998) argumenta que a cultura organizacional é constituída pelo imaginário e símbolos, sendo manifesta nos princípios, valores, conhecimentos, técnicas, códigos, tabus, estilos, juízos, usos e costumes. Mintzberg et al. (2000) esclarecem que a cultura é a base da organização, pois esta traz as crenças da organização refletidas nas suas tradições, hábitos, símbolos e até em seus produtos. A força dessa cultura está na sua capacidade de autenticar suas crenças e valores que são compartilhados na organização (PIRES; MACÊDO, 2006).

Diante dessa ótica, a cultura traz a identidade da organização, podendo, segundo Dupuis (1996), ser um instrumento moldado pelos gestores de acordo com seus interesses. Assim, Smith et al. (2013) trazem que a cultura se manifesta nas maneiras similares de comportamento praticado por um grupo, seja na forma semelhante de reação a um contexto, na forma semelhante no processamento de uma informação ou na interpretação compartilhada do significado de um fenômeno.

Para Freitas (2005), é através da cultura organizacional que se institucionaliza o que é importante, qual a forma correta de pensar e agir e quais são os comportamentos aceitáveis. Seguindo essa concepção, Davis (1984) considera a cultura organizacional como a que fornece significado aos membros da organização.

Dada a importância da cultura organizacional, entendê-la profundamente é fator crucial para o desenvolvimento de uma liderança eficiente, uma vez que a cultura que está estabelecida em um ambiente organizacional é responsável por guiar e restringir o comportamento dos membros desse grupo. Entendendo que o estudo dessa cultura trata de aspectos que, muitas vezes, não estão disponíveis à percepção, estudá-la, conhecê-la e entendê-la é conhecer a si e aos outros que compartilham o mesmo ambiente, a um nível profundo, criando alternativas para se gerir melhor as pessoas e a si, desenvolvendo estratégias eficazes e trazendo a possibilidade de moldar, administrar e agir sobre a cultura estabelecida (SCHEIN, 2009). Conhecer a cultura da organização é importante pois, segundo Russo (2010), esta é responsável por dar consistência às ações da organização e dos seus colaboradores, trazendo ordem nos relacionamentos e nas atividades da empresa, podendo levar a empresa por direções corretas, ou não.

Russo (2010) apresenta formas de se conhecer a cultura por meio da criação de modelos de diagnósticos culturais, que têm como objetivo classificar, esclarecer e definir as características da cultura analisada. Em seu livro 'Diagnóstico da Cultura Organizacional', o referido autor ressalta exemplos de vários modelos de diagnósticos que são utilizados para estudar e se aprofundar no entendimento da cultura em organizações, elencando como um dos principais o modelo de Geert Hofstede, que será tomado como base no diagnóstico cultural da presente pesquisa. Geert Hofstede focou nas diferenças e semelhanças entre culturas de organizações de nações diferentes, avaliando quatro dimensões: Distância Hierárquica, Grau 
de Controle da Incerteza, Grau de Individualismo ou Coletivismo e Características Culturais Femininas ou Masculinas. O referido modelo foi desenvolvido inicialmente para diagnóstico de culturas nacionais, todavia, também já foi aplicado fidedignamente a culturas organizacionais, a exemplo de Alcântara et al. (2010). A seguir, apresentar-se-ão conceitualmente as quatro dimensões culturais de Geert Hofstede, que foram utilizadas no presente estudo.

\section{DIMENSÕES CULTURAIS DE HOFSTEDE}

Geert Hofstede é, mundialmente, um dos estudiosos mais conceituados na área de cultura nacional e de cultura organizacional, consagrando-se quando desenvolveu um estudo, entre 1968 e 1972, com mais de 60 países, entrevistando mais de 160 mil pessoas, no qual observou que a cultura é parte crucial na formação do modo de se gerir. Neste estudo, Hofstede analisou as organizações segundo quatro dimensões por ele identificadas: Distância do Poder, Necessidade de Controlar as Incertezas, Grau de Individualismo versus Coletivismo e Masculinidade versus Feminilidade (TANURE, 2010). Russo (2010) apresenta a definição das quatro dimensões de Hofstede.

a) Distância do Poder: mede o quanto o poder é distribuído na sociedade e o quanto as pessoas aceitam essa distribuição. Na referida medição, é levado em consideração o nível de participação nas tomadas de decisão e o quanto as pessoas têm acesso à informação. Quando o Índice de Distância de Poder é baixo, indica-se que nesta organização prevalece a descentralização do poder, as pessoas esperam ser consultadas e a liderança é democrática, enquanto nas organizações nas quais o índice é alto, a concentração do poder prevalece, os funcionários esperam ser delegados e a liderança é não democrática e soberana nas decisões.

b) Necessidade de Controlar as Incertezas: também conhecida como 'Aversão à Incerteza', mede o quanto as empresas investem em planejamento, estruturação, formalização para reduzir imprevistos e incertezas. As organizações que apresentam alto Índice de Controle das Incertezas apresentam pessoas acostumadas com muitas regras e normas, tendo um ambiente intolerante com desvios de comportamentos e de ideias, mantendo um rígido controle dos comportamentos e crenças. Organizações que apresentam índices baixos são mantidas com quantidades menores de regras, tendendo a ser mais flexíveis, relevando mais facilmente alguns desvios de comportamento.

c) Grau de Individualismo versus Coletivismo: mede o quanto as organizações possuem de valores individualistas ou coletivistas, levando em consideração o quanto estas enfatizam o papel do indivíduo em detrimento do grupo. Organizações com Índice de Individualismo elevado possuem indivíduos que acreditam serem suficientes para cuidar sozinhas de seus trabalhos e família, dando mais importância à liberdade na hora de executarem suas tarefas. Em organizações com índice baixo, consideradas organizações coletivistas, existe valorização do trabalho em grupo, estreitamento das relações sociais e 
desvalorização da liberdade individualista.

d) Masculinidade versus Feminilidade: mede o quanto as organizações tendem a valorizar valores masculinos em detrimento de valores femininos. Entende-se por valores masculinos altos ganhos, competitividade, ambição, auto realização, enquanto os valores femininos são entendidos como zelo, solidariedade, relações interpessoais, preferência pela qualidade de vida.

\section{CULTURA ORGANIZACIONAL NO TERCEIRO SETOR}

Haja vista que o presente estudo analisará a cultura organizacional de duas filiais (regionais) de uma empresa pertencente ao terceiro setor, é salutar que se contextualize essa tipologia de organização.

De acordo com Falconer (1999), as organizações do terceiro setor possuem cultura diferenciada, com padrões próprios, quando comparadas com organizações do setor público e empresas privadas com finalidade de lucro. Isto, segundo o autor, se deve, principalmente, à motivação dos funcionários e voluntários que compõem este tipo de organização, pois estes são impelidos pelos valores e missão pregados pela mesma, trazendo no ambiente interno um alto nível de engajamento, sendo a missão, os objetivos e a realização dos mesmos mais importantes que as recompensas individuais.

Orsi et al. (2005) dizem que os fatores que influenciam a cultura das organizações com fins lucrativos são iguais aos fatores que influenciam a cultura das organizações do terceiro setor, sendo estes a história da organização, a estrutura organizacional, as relações internas, as práticas gerenciais, os sistemas de comunicação e o sistema de recompensas. Entretanto, as organizações sem fins lucrativos possuem um fator que as diferenciam de forma intensa. Segundo os autores, esse fator é a crença das pessoas na causa pela qual trabalham. Isto traz uma alta motivação, que pode levar pequenos grupos a realizar muitas ações sociais.

Quanto à gestão destas organizações, os líderes, segundo Falconer (1999), na gestão, no planejamento e nos processos decisórios trabalham de forma participativa, tendendo a manter relacionamentos com os colaboradores pautados em valores como proximidade, confiança e harmonia. Tal ambiente é característica marcante das organizações do terceiro setor e contribui para a satisfação das pessoas que compõe a organização.

\section{MATERIAL E MÉTODOS}

A abordagem da presente pesquisa foi quantitativa-descritiva, que, segundo Duarte e Furtado (2002), descreve um fenômeno ou situação mediante um estudo realizado em determinado contexto espacial e temporal, tendo como objetivo descrever as características de determinada população, ou fenômenos que ocorrem no objeto pesquisado. 
O presente estudo delimitou-se em comparar dimensões culturais de duas regionais de uma empresa do terceiro setor do estado de Minas Gerais (MG): uma localizada na região norte do estado - aqui chamada de 'Regional A' - e outra na região Metropolitana de Belo Horizonte-MG - aqui chamada de 'Regional B'.

A organização do terceiro setor tomada para análise atua no estado de Minas GeraisMG há 47 anos, criada em 1972 como uma entidade vinculada ao Governo Federal, sendo, em 1990, desvinculada do poder público, tornando-se uma instituição privada, sem fins lucrativos, enquadrando-se no terceiro setor. Hoje, conta com uma estrutura departamentalizada em 9 regionais espalhadas em todo o território do estado, tendo sido escolhidas apenas duas por questão de acessibilidade.

Para o desenvolvimento da pesquisa, utilizou-se de instrumentos de coleta de dados primários e secundários. A coleta de dados secundários se referiu às pesquisas bibliográficas realizadas em livros, revistas científicas e artigos científicos, que trouxeram base teórica para o tema. A coleta de dados primários, por sua vez, foi feita através de um questionário fechado, com uma escala de mensuração de cultura adaptados dos autores Alcântara et al. (2010). Tal questionário é formado por 33 questões divididas em duas partes. A primeira contém 4 questões sobre o perfil dos respondentes, e a segunda 28 questões sobre as suas percepções quanto ao ambiente de trabalho no qual estão inseridos. O período de coleta dos dados foi entre os dias 5 de dezembro de 2017 e 9 de abril de 2018.

A amostragem adotada na pesquisa foi do tipo probabilística aleatória, que é definida por Kauark, Manhães e Medeiros (2010) como a amostragem onde todos os membros da população possuem oportunidades iguais de serem incluídos, sem que haja critério específico para isso. $O$ instrumento de coleta de dados (questionário) foi enviado por e-mail, por meio da ferramenta Google Docs, sendo que, na 'Regional A', 32 colaboradores o receberam e 27 o responderam (taxa de retorno: 84\%), enquanto que, 'na Regional B' 41 colaboradores o receberam, com 27 respondentes (taxa de retorno: 66\%). Anteriormente à aplicação do questionário, os respondentes foram informados de que o seu anonimato e da empresa seriam garantidos.

A presente pesquisa tratou-se de um 'estudo multicaso', uma vez que foram coletados e posteriormente comparados os dados de duas diferentes regionais da referida organização do terceiro setor. O método multicaso permite maior abrangência dos resultados, ultrapassando os limites de unicidade de dados obtidos em um único objeto de estudo. 0 estudo multicaso é aquele no qual se analisam informações de diferentes organizações, ao contrário do estudo de caso que analisa apenas uma (YIN, 2005). Ademais, essa abordagem comparativa foi escolhida no intuito de verificar se havia diferenças significativas nas culturas organizacionais das duas regionais de uma mesma empresa.

Para a mensuração da cultura organizacional, foi utilizada a segunda parte do 
questionário que contém uma escala do tipo Likert, levando em consideração as quatro dimensões de Hofstede (1980): Índice de Distância Hierárquica (IDH), Índice de Individualismo (INDI), Índice de Masculinidade (MASC) e o Índice de Controle da Incerteza (CINC). Cada dimensão possui, no questionário, 7 questões, cada uma com 5 alternativas, variando entre 1Discordo Totalmente e 5- Concordo Totalmente.

\section{$\sum[1,2,3,4,5]=15$}

Levando-se em conta que a soma dos itens possíveis para a resposta resulta em 15, infere-se que a média aritmética é 3 (15/5). Diante disso, fez-se o cálculo do redutor da amplitude das faixas de pontuação, seguindo os procedimentos adotados por Alcântara et al. (2010), da forma que se segue:

$\Re=M . N j$, sendo $\mathfrak{R}$ o fator redutor, $\mathrm{M}$ a média, e $\mathrm{Nj}$ o número de itens de cada dimensão. Logo:

$\mathfrak{R}=21$

Com aplicação do fator redutor, obtiveram-se as seguintes faixas de pontuação:

Tabela 1 - Faixas de Pontuação com aplicação do Fator Redutor

\begin{tabular}{lll}
\hline Pontuação por dimensão & Sem Fator Redutor & Com Fator Redutor \\
& & \\
\hline Máxima & $5 * 7=35$ & $35-21=14$ \\
Média & $3 * 7=21$ & $21-21=0$ \\
Mínima & $1 * 7=7$ & $7-21=-14$ \\
\hline
\end{tabular}

Fonte: Adaptado de Alcântara et al (2010).

Assim, determinou-se, para cada índice de dimensão cultural, as seguintes faixas de pontuação de intensidade: de -14 a $-8,4$, considerou-se a intensidade muito baixa; de $-8,4$ a 2,8, considerou-se a intensidade baixa; de $-2,8$ a 2,8, considerou-se a intensidade pouco elevada; de 2,8 a 8,4, considerou-se a intensidade elevada; de 8,4 a 14, considerou-se a intensidade muito elevada.

O resultado registrado para cada índice de dimensão cultural, das duas regionais estudadas, foi encontrado subtraindo da média de cada índice o fator redutor 21 , levando cada um dos valores encontrados a se enquadrar em uma das faixas de pontuação acima descritas. 


\section{RESULTADOS E DISCUSSÃO}

A análise dos resultados será apresentada em duas seções. Na primeira parte, apresentar-se-á o perfil dos entrevistados e, na segunda, o resultado da aplicação da escala de mensuração da cultura organizacional nas duas regionais estudadas.

PERFIL DOS ENTREVISTADOS

\section{Regional A}

Dos 27 respondentes da 'Regional A', 44\% eram do sexo masculino e $56 \%$ do sexo feminino. 85\% possuíam de 20 a 40 anos, enquanto $15 \%$ mais de 40 anos, não sendo registrado respondente com menos de 20 anos. Quanto à formação acadêmica, identificou-se que a maioria dos respondentes possuía ou estava cursando uma pós-graduação (52\%), enquanto $48 \%$ possuíam ou estavam cursando uma graduação. No que se refere ao tempo de trabalho na empresa em questão, registrou-se que 59\% estavam na empresa há menos de 3 anos, 15\% entre 3 a 6 anos, 15\% entre 6 e 9 anos e 11\% há 12 anos ou mais.

\section{Regional B}

Dos 27 respondentes na 'Regional B', 11\% eram do sexo masculino e $89 \%$ do sexo feminino. 67\% encontravam-se na faixa etária entre 20 e 40 anos, 30\% entre 40 e 60 anos e 3\% com mais de 60 anos.

Quanto à escolaridade, $3 \%$ possuíam ensino médio completo, $45 \%$ possuíam ou estavam cursando o ensino superior e $52 \%$ possuíam pós-graduação completa.

Em relação ao tempo de trabalho na empresa, 22\% estavam na empresa há menos de 3 anos, 33\% entre 3 e 6 anos, 19\% entre 6 e 9 anos, 15\% de 9 a 12 anos e 11\% há mais de 12 anos.

\section{RESULTADO DA APLICAÇÃO DA ESCALA DE MENSURAÇÃO DA CULTURA ORGANIZACIONAL}

No Gráfico 1, são apresentados os resultados gerais ('Regional A' + 'Regional B'), contendo as médias referentes às quatro dimensões analisadas neste estudo, índice de Distância Hierárquica (IDH), Índice de Individualismo (INDI), Índice de Masculinidade (MASC) e o Índice de Controle da Incerteza (CINC). Os dados das duas regionais foram inicialmente apresentados em conjunto com o intuito de representar a organização do terceiro setor analisada e permitir que suas dimensões culturais fossem comparadas com as dimensões da cultura brasileira segundo Hofstede (2010). Posteriormente, serão caracterizadas as duas regionais em separado. 
Gráfico 1 - Média geral das quatro dimensões para as duas regionais em conjunto

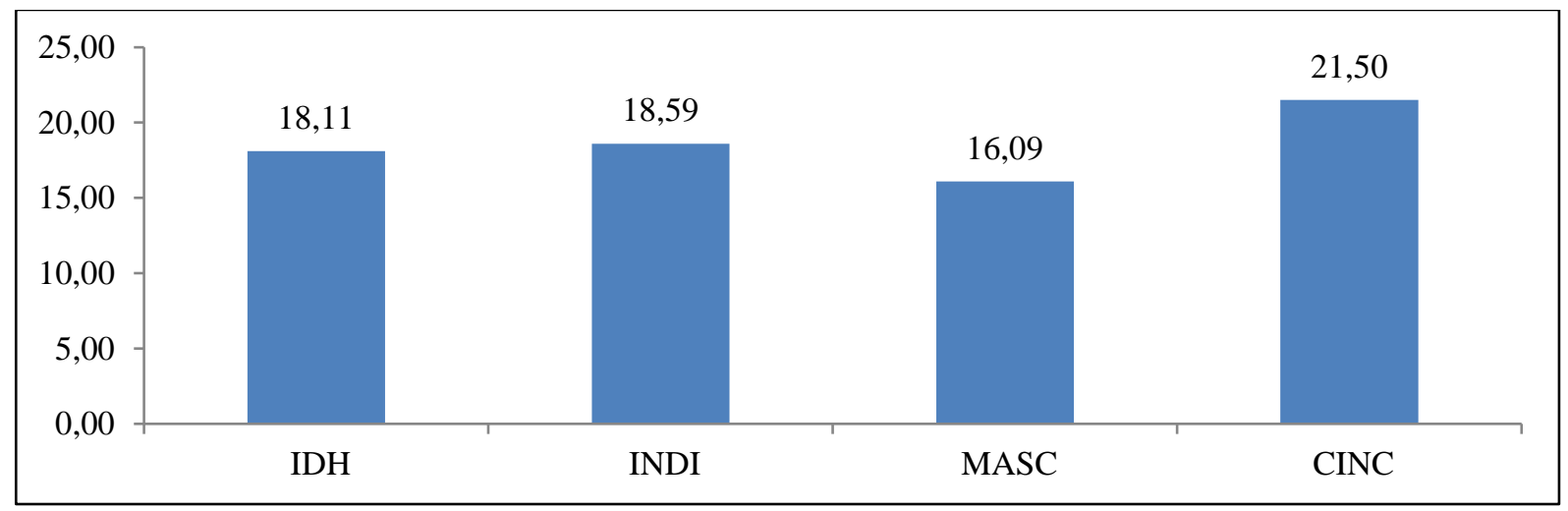

Fonte: Dados da pesquisa (2019).

Baseando-se nesses resultados gerais, é possível identificar que o índice de maior valor foi o Índice de Controle da Incerteza (CINC) e o menor foi o Índice de Masculinidade (MASC). Esses dados apontam que os funcionários das duas regionais, quando analisados em conjunto, apresentam uma alta aversão à incerteza em suas tarefas laborais. Ademais, não valorizam demasiadamente altos ganhos, competitividade e ambição, que são características típicas da masculinidade segundo Hofstede (1980). De acordo com os estudos de Geert Hofstede (2010), o Brasil, quando analisado pelo autor quanto a sua cultura, apresentou o Índice de Controle da Incerteza como o maior índice (86, numa escala de 0 a 100) e apresentou o Índice de Masculinidade baixo (49, numa escala de 0 a 100). Isso permite inferir que as dimensões culturais das duas regionais estudadas estão compatíveis com as dimensões da cultura brasileira.

De acordo com Russo (2010), as empresas ou sociedades que possuem alto Índice de Controle da Incerteza apresentam como características muitas regras e normas, com controle rígido do comportamento e crenças, punindo os desvios. Para Hofstede (2010), ambientes com pontuação elevada no Índice de Controle da Incerteza são compostos por pessoas que acreditam que burocracias, leis e regras são cruciais para manter aquela sociedade em questão mais segura para se viver.

Russo (2010) argumenta que empresas que possuem o Índice de Masculinidade baixo primam por valores femininos, sendo estes o zelo, solidariedade, relações interpessoais e preferência pela qualidade de vida. Em seu estudo, Hofstede (2010) define que uma sociedade com Índice de Masculinidade baixo não se motiva buscando ser o melhor e sim buscando melhor qualidade de vida, preocupando-se com o que faz e como se faz.

Conforme demonstrado no Gráfico 1, a pesquisa também apontou valores baixos para os seguintes índices: Índice de Distância Hierárquica (IDH) e Índice de Individualismo (INDI). Segundo Hofstede (2010), o Brasil possui valor baixo para o Índice de Individualismo (38, numa escala de 0 a 100) e valor alto para o Índice de Distância Hierárquica (69, numa escala de 0 a 
100), sendo este último o único índice que não apresenta resultado semelhante nas duas pesquisas, isto é, quando se comparam os resultados das duas regionais estudadas na presente pesquisa com os resultados do estudo para a cultura brasileira como um todo. Uma hipótese para essa discrepância é o fato de a empresa analisada faz parte do terceiro setor, em que, teoricamente, as decisões são tomadas em conjunto e existe maior acesso dos colaboradores aos setores gerenciais. Esse resultado está compatível com Tachizawa (2007), segundo o qual as organizações do terceiro setor tendem a ter gestão participativa e democrática.

Analisando tais índices, de acordo com Russo (2010), as organizações que apresentam Índice de Distância Hierárquica baixo possuem como característica a descentralização do poder, liderança democrática e as pessoas que as compõem esperam que, nas tomadas de decisão, elas sejam consultadas. Ainda de acordo com o referido autor, as organizações que possuem Índice de Individualismo baixo apresentam valorização do coletivismo, do trabalho em grupo e das relações sociais.

Os índices MASC e IDH, nos resultados gerais ('Regional A' + 'Regional B'), apresentam médias baixas, corroborando as características do terceiro setor defendidas por Tachizawa (2007), como gestão descentralizada e democrática, tendo como valores centrais o zelo e a solidariedade.

Levando-se em consideração as definições de subculturas já apresentadas, em que os autores Morgan (2006) e Triandis (2002) trazem a possibilidade de grupos possuírem comportamentos distintos entre si, dentro de um mesmo ambiente ou organização, neste estudo será feita uma comparação entre os resultados obtidos para cada regional de forma isolada (estudo multicaso), buscando verificar se existem evidências de que a cultura de cada regional representa uma subcultura da empresa analisada.

Na Tabela 2, apresentam-se os resultados obtidos para cada regional, com as médias para cada índice ou dimensão cultural. Após a aplicação do fator redutor, conforme descrito na seção de procedimentos metodológicos, obteve-se a intensidade de cada índice em cada regional.

Tabela 2 - Média, média com fator redutor e intensidade por regional.

\begin{tabular}{lllll}
\hline Índice & Regional & Média & Aplicação do Fator Redutor & Intensidade \\
\hline IDH & A & 17,04 & $-3,96$ & Baixa \\
& B & 19,19 & $-1,81$ & Um pouco elevada \\
\hline INDI & A & 19,04 & $-1,96$ & Um pouco elevada \\
& B & 18,15 & $-2,85$ & Baixa \\
\hline MASC & A & 16,33 & $-4,67$ & Baixa \\
& B & 15,85 & $-5,15$ & Baixa \\
\hline CINC & A & 22,93 & 1,93 & Um pouco elevada \\
& B & 20,07 & $-0,93$ & Um pouco elevada
\end{tabular}


Fonte: Dados da pesquisa (2019).

Diante dos dados obtidos pela pesquisa, conforme Gráfico 2, pode-se verificar que as duas regionais possuem maior média no Índice de Controle da Incerteza (CINC) e menor no Índice de Masculinidade (MASC). Nestes dois índices, as regionais apresentam o mesmo grau de intensidade, sendo para o CINC 'um pouco elevada' e para o MASC 'baixa'.

Gráfico 2 - Média das quatro dimensões por regional

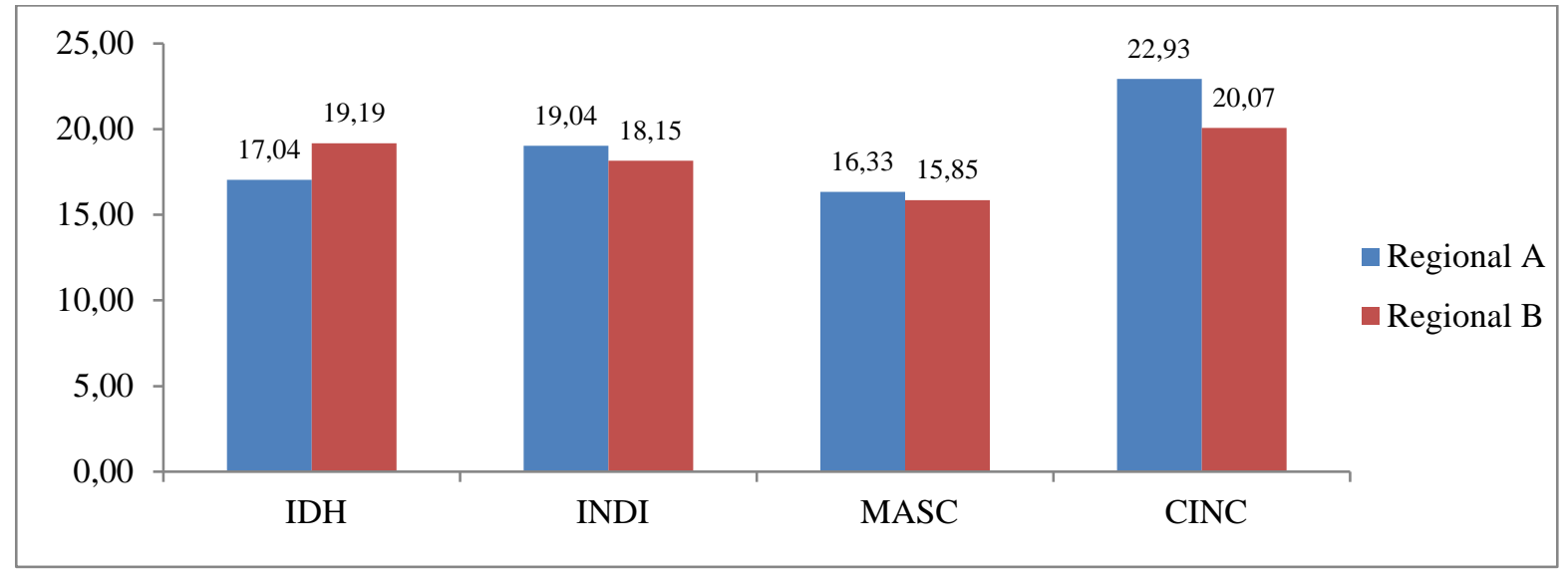

Fonte: Dados da pesquisa (2019).

Apesar de apresentar a maior média nas duas regionais e apresentar o mesmo grau de intensidade, o Índice de Controle da Incerteza (CINC), em relação à média apresentada, é o que apresenta maior diferença entre as duas regionais. A 'Regional A' apresenta média superior em 2,85, o que demonstra ter maior tendência ao controle das incertezas, preferindo um ambiente regido por mais normas e leis, segundo Hofstede (2010).

Em relação ao Índice de Masculinidade, verifica-se que este foi o que apresentou menos distância entre as regionais, em relação a sua média, sendo que apresenta uma variação de 0,48 , o que demonstra que as regionais possuem, de forma semelhante, um ambiente que valoriza a qualidade de vida (HOFSTEDE, 2010), regidos pelo zelo e pela solidariedade (RUSSO, 2010).

Nos índices IDH e INDI, as regionais apresentaram intensidades diferentes. $\mathrm{Na}$ 'Regional A', O IDH apresenta intensidade 'baixa' enquanto que, na 'Regional B', o mesmo apresenta intensidade 'um pouco elevada', representando o segundo índice com maior diferença entre as médias (diferença de 2,15). Esses resultados indicam que a 'Regional A' possui uma subcultura organizacional em que os colaboradores percebem com maior intensidade uma liderança mais democrática e consultiva (RUSSO, 2010).

Quanto ao Índice de Individualismo, a 'Regional A' apresenta intensidade 'um pouco elevada', enquanto a 'Regional B' apresenta intensidade 'baixa', possuindo médias com distância de 0,89. Entende-se, portanto, que, na 'Regional $A^{\prime}$ ', a subcultura organizacional 
instalada demonstra menor valorização do coletivismo que na 'Regional B', segundo Russo (2010).

\section{CONSIDERAÇÕES FINAIS}

Fazendo uso de escalas de dimensões culturais já validadas em estudos anteriores, o presente estudo buscou comparar duas regionais de uma organização do terceiro setor do Estado de Minas Gerais-MG, tomando como base as dimensões culturais da teoria de Hofstede (1980). Por meio do levantamento da intensidade de quatro dimensões culturais, o estudo comprovou que existem diferenças na cultura instalada em cada regional, o que aponta para a existência de duas subculturas, em especial quanto ao Índice de Controle de Incerteza (CINC) e ao Índice de Distância Hierárquica (IDH). Esses resultados jogaram luz na hipótese de que, mesmo que uma organização se esforce no sentido de disseminar seus valores culturais, objetivando que seus colaboradores assumam pensamentos uníssonos e consoantes com os objetivos institucionais (SHEIN, 2009), a existência de subculturas dentro de uma organização pode fazer, por exemplo, com que empresas filiais de uma organização matriz apresentem particularidades que desviem, em maior ou menor grau, dos valores desta como um todo.

Robbins, Judge e Sobral (2010) chamam a atenção para os problemas que podem acontecer em uma organização que tende a apresentar em seu interior inconsistências quanto à cultura, sendo que, nessa situação, a cultura tende a ser fraca conforme aumentam tais inconsistências, podendo comprometer o desenvolvimento da missão da organização, bem como o alcance de seus objetivos. Infere-se, portanto, que as inconsistências entre as subculturas representadas por cada regional/filial podem, em última análise, dificultar o alcance dos objetivos organizacionais, mormente em organizações do terceiro setor, cuja cultura é diferenciada, com padrões próprios, quando comparadas com organizações do setor público e empresas privadas com finalidade de lucro (FALCONER, 1999).

Apesar das diferenças apresentadas, o Índice de Masculinidade (MASC) apresentou médias baixas tanto no resultado geral como na análise de cada regional separadamente. Isso aponta, segundo Russo (2010) e Hofstede (2010), que a organização do terceiro setor analisada tem como base valores e princípios chamados de 'femininos'. Enquanto os valores masculinos são altos ganhos, competitividade, ambição, auto realização, os valores femininos são zelo, solidariedade, relações interpessoais e preferência pela qualidade de vida. Os resultados indicam que, conforme a cultura desta organização, seu objetivo principal não é o sucesso econômico e de mercado, mas sim buscar qualidade de vida para seus colaboradores, os quais demonstram zelo e solidariedade em suas atividades laborais e se identificam com os fins de interesse público. Esses resultados em específico mostraram-se compatíveis com as características gerais de uma organização do terceiro setor, evidenciando que a mesma não objetiva o lucro primordialmente, mas trabalha para o desenvolvimento da sociedade, 
defendendo os direitos da população (VOLTOLINI, 2003).

Uma das principais reflexões e contribuições levantadas por este trabalho diz respeito ao fato de que as peculiaridades de cada cultura organizacional precisam ser levadas em consideração quando do estabelecimento de objetivos e métricas de controle, mesmo que as organizações façam parte de uma mesma empresa. A partir disso, infere-se que pode ser arriscado tratar empresas filiais de forma homogênea, haja vista que a existência de subculturas pressupõe diferenças importantes na forma como seus colaboradores interpretam os diversos contextos nos quais estão inseridos, bem como o seu comportamento. Depreende-se, portanto, que a cultura organizacional de cada uma das duas regionais aqui estudadas pode ser considerada uma subcultura, pois diferem-se em algumas dimensões culturais, apesar de algumas similaridades que Ihes trazem identidade. Essa situação, na qual um grupo possui algumas características que o diferencia de outro grupo, segundo Triandis (2002), caracterizase como subcultura, apesar dos esforços gerais de uma empresa em difundir seus princípios, valores e normas para todas as filiais.

Como limitação desta pesquisa, apresenta-se o fato de se ter envolvido apenas duas das nove unidades da empresa do terceiro setor em todo o território do estado de Minas Gerais-MG, limitação esta justificada por questões de acessibilidade. Visando ao aprofundamento deste estudo, sugere-se que futuras pesquisas sejam realizadas abarcando mais de uma organização do terceiro setor, com vista a entender o ambiente, as motivações e os desafios destas organizações, bem como a existência de subculturas. Ademais, sugere-se a adoção de outras escalas de mensuração cultural, a exemplo de métricas já validadas internacionalmente como a de House et al. (2004), a de Trompenaars e Hampden-Turner (2012), a de Inglehart (1997) ${ }^{4}$ e a de Schwartz et al. (2012).

Encerra-se este estudo, esperando ter contribuído para o mapeamento cultural da organização do terceiro setor analisada, trazendo benefícios para a mesma ao permitir aos seus gestores um conhecimento mais profundo de duas de suas filiais. Ademais, espera-se ter colaborado academicamente para o aprofundamento da área de estudos organizacionais, mormente para o estudo de culturas organizacionais.

\section{REFERÊNCIAS}

AKTOUF, O. O simbolismo e a cultura da empresa: dos arcabouços conceituais às lições empíricas. In: CHANLAT, J. F. (Org.) O indivíduo na organização: dimensões esquecidas. São Paulo: Atlas, 2007, v. III.

ALCÂNTARA, V. C.; ANDRADE, L. F. S.; MENESES, R. S. S.; GOD, P. I. G. Mensuração da Cultura Organizacional: Uma análise quantitativa-comparativa. RECADM. Paraná, v. 9, n. 2, p. 213-

${ }^{4}$ A obra de Inglehart (1997) é considerada um clássico no campo de estudos culturais. 
232, Novembro. 2010.

DAVIS, S.M. Managing Corporate Culture. 1 Ed. Cambridge: Harper \& Row, 1984.

DUARTE, S. V.; FURTADO, M. S. V. Manual para elaboração de monografias e projetos de pesquisa. 3. Ed. Montes Claros: Unimontes, 2002.

DUPUIS, J. P. Antropologia, cultura e ação: proposta de um modelo construtivista. In: CHANLAT, J. F (Org.) O indivíduo e as organizações: dimensões esquecidas. 2.ed. São Paulo: Atlas, 1996.

FALCONER, A. P. A promessa do Terceiro Setor: um estudo sobre a construção do papel das organizações sem fins lucrativos e do seu campo de gestão. Dissertação (Mestrado). São Paulo: FEA-USP, 1999.

FREITAS, M. E. de. Cultura organizacional: identidade, sedução e carisma. 4.Ed. Rio de Janeiro: FGV, 2005.

HOFSTEDE, G. Country Comparison. In: Hofstede Insights. 2010. Disponível em < https://www.hofstede-insights.com/country-comparison/denmark/> visitado em 21 de Março de 2018.

HOFSTEDE, G. Culture's consequences: International differences in work-related values. Beverly Hills: Sage. 1980.

HOUSE, R. J.; HANGES, P. J.; JAVIDAN, M.; DORFMAN, P. W.; GUPTA, V. Culture, leadership and organizations: The GLOBE study of 62 societies. Thousand Oaks, CA: Sage, 2004.

INGLEHART, R. Modernization and postmodernization: Cultural, economic, and political change in 43 societies. Princeton, NJ: Princeton University Press, 1997.

KAUARK, F. S; MANHÃES, F. C; MEDEIROS, C. H. Metodologia da Pesquisa: um guia prático. Itabuna-BA: Via Litterarum, 2010.

LARAIA, R. de B. Cultura um conceito Antropológico. 23. ed. Rio de Janeiro: Zahar, 2009.

LOURENÇO, N. R. A.; DOS SANTOS J. P. C. Assistencialismo versus Emancipação: o papel do terceiro setor na sociedade atual. Revista de Saúde Pública, São Paulo, v.12, p. 10-14, Junho. 2010.

MINTZBERG et al. Safári de Estratégia: um roteiro pela selva do planejamento estratégico. Porto Alegre: Bookman, 2000;

MORGAN, G. Imagens da organização. 2. ed. São Paulo: Atlas, 2006.

MOTTA, F. C. P.; CALDAS, M. P. Cultura organizacional e cultura brasileira. São Paulo: Atlas, 1997. 
ORSI, A.; MARINO, E.; ROSSI, L.; BERTOIA, N.; SHINIASHIKI, R. Cultura Organizacional e Terceiro Setor. Revista Gestão e Conhecimento - FACET, volume 3, no 1, Curitiba, 2005.

PIRES, J. C de S.; MACÊDO, B. K. Cultura organizacional em organizações públicas no Brasil. RAE. Rio de Janeiro. v. 40, n. 1, p. 81-105, jan/fev.2006.

ROBBINS, S. P.; JUDGE, T. A.; SOBRAL, F. Comportamento organizacional: Teoria e prática no contexto brasileiro, 14 edição, Pearson, São Paulo, 2010.

RUSSO, G. M. Diagnóstico da Cultura Organizacional: O Impacto dos Valores Organizacionais no Desempenho das Terceirizações. 1. Ed. São Paulo: Dedix, 2010.

SCHEIN, E. Cultura Organizacional e Liderança. São Paulo: Atlas, 1985.

SCHWARTZ, S. H.; CIECIUCH, J.; VECCHIONE, M.; DAVIDOV, E.; FISCHER, R.; BEIERLEIN, C.; RAMOS, A.; VERKASALO, M.; LÖNNQVIST, J. E.; DEMIRUTKU, K.; DIRILEN-GUMUS, O.; KONTY, $M$. Refining the theory of basic individual values. Journal of Personality and Social Psychology, v. 103,2012 , p. 663-688.

SMITH, P. B.; FISCHER, R.; VIGNOLES, V. L.; BOND, M. H. Understanding Social Psychology Across Cultures: Engaging with Others in a Changing World, London: Sage, 2013.

SROUR, R. H. Poder, Cultura e Ética nas organizações. 8 ed. Rio de Janeiro: Campus, 1998.

TACHIZAWA, Takeshy. Organizações Não Governamentais e Terceiro Setor. 3. Ed. São Paulo: Atlas, 2007.

TRIANDIS, H. C. Subjective Culture. Online Readings in Psychology and Culture, v. 2, n. 2, 2002, p. 1-12.

TANURE, Betânia. Gestão à Brasileira: Uma Comparação entre América latina, Estados Unidos, Europa e Ásia. 2. Ed. São Paulo: Atlas, 2010.

TROMPENAARS, F.; HAMPDEN-TURNER, C. Riding the waves of culture: Understanding cultural diversity in business. 3. ed. London: Nicholas Brealey, 2012.

VOLTOLINI, R. Terceiro Setor: planejamento e gestão. 2. Ed. São Paulo: Senac, 2003.

YIN, R. K. Estudo de caso: planejamento e métodos. 3. ed. Porto Alegre: Bookman, 2005. 